\title{
Aspectos clínicos e tomográficos de exostose mandibular extensa e o seu manejo para melhora na qualidade de vida: relato de um caso incomum na literatura
}

Clinical and tomographic aspects of extensive mandibular exostoses and their management to improve quality of life: report of an unusual case in the literature

Aspectos clínicos y tomográficos de excisis mandibular extensa y su manejo para mejora en la calidad de vida: relato de un caso inusual en la literatura

Carlos Fernando de Almeida Barros MOURÃO'

Rafael Coutinho de MELLO-MACHADO ${ }^{2}$

Rodrigo Figueiredo de Brito RESENDE ${ }^{3}$

Flavia Santos FERREIRA 4

Mônica Diuana CALASANS-MAIA ${ }^{5}$

IPós- Doutorado, Universidade Federal Fluminense (UFF), 24220-900 Niteroi-RJ, Brasil;

Professor Visitante, Università degli Studi di Genova, UNIGE, Itália; Marinha do Brasil, MB-Brasil

${ }^{2}$ Programa de Pós-Graduação em Odontologia, Universidade Federal Fluminense (UFF), 24220-900 Niteroi-RJ, Brasil

${ }^{3}$ Professor das Disciplinas de Cirurgia Oral Menor e Anestesiologia da Universidade Federal Fluminense (UFF), 24220-900 Niteroi-RJ, Brasil

${ }^{4}$ Capitão-Tenente pelo Corpo de Saúde da Marinha do Brasil, Marinha do Brasil, MB-Brasil

${ }_{5}^{5}$ Professora Titular da Disciplina de Cirurgia Oral Menor da Universidade Federal Fluminense (UFF), 24220-900 Niteroi-RJ, Brasil

\section{Resumo}

O tórus mandibular é considerado uma protuberância óssea (exostose) de etiologia desconhecida classificada como não-patológica, comumente vista em região lingual dos incisivos até pré-molares inferiores. Sua característica histopatológica é semelhante ao osso normal descrevendo-se osso cortical lamelar com a presença de canais de Havers, osteócitos normais e áreas dispersas de tecido conjuntivo. Normalmente se apresentam bilateralmente e indolores. Sem causar prejuízo na vida da pessoa que apresenta esta condição, devido estes aspectos, na maioria dos casos, não há intervenção cirúrgica, sendo o caso apenas acompanhado clinicamente. Neste caso apresentado, o objetivo é expor uma condição extrema desta exostose mandibular, tendo como finalidade a melhora na qualidade de vida do paciente.

Descritores: Cirurgia Bucal; Exostose; Qualidade de Vida.

\section{Abstract}

The mandibular torus is considered a bone protuberance (exostosis) of unknown etiology classified as non-pathological, commonly seen in the lingual region from the mandibular incisors to premolars. Its histopathological characteristic is similar to normal bone constituting lamellar cortical bone with the presence of Haversian channels, normal osteocytes and scattered areas of tissue containing connective tissue. They usually present bilaterally and painless. Without causing damage to the life of the person who shows this condition, due to these aspects, in most cases, there is no surgical intervention, being the case only followed clinically. In this case, the aim is to expose an extreme condition of this mandibular exostosis, with the purpose of improving the quality of life of the patient.

Descriptors: Surgery, Oral; Exostoses; Quality of Life.

\section{Resumen}

El tórus mandibular se considera una protuberancia ósea (exostosis) de etiología desconocida clasificada como no patológica, comúnmente vista en región lingual de los incisivos hasta pre-molares inferiores. Su característica histopatológica es similar al hueso normal constituyéndose por hueso cortical lamelar con la presencia de canales de Havers, osteocitos normales y áreas dispersas de tejido que contiene tejido conectivo. Normalmente se presentan bilateralmente e indolores. Sin causar daño en la vida de la persona que presenta esta condición, debido a estos aspectos, en la mayoría de los casos, no hay intervención quirúrgica, siendo el caso sólo acompañado clínicamente. En este caso presentado, el objetivo es exponer una condición extrema de esta excisose mandibular, teniendo como finalidad la mejora en la calidad de vida del paciente.

Descriptores: Cirugía Bucal; Exostosis; Calidad de Vida.

\section{INTRODUÇÃO}

As exostoses, como os tórus, são considerados uma protuberância óssea de etiologia desconhecida classificada como não patológica (benigna), comumente vista em região de maxila (palato) e em região mandibular lingual (mais comumente em região de pré-molares e caninos). A literatura apresenta taxas diferenciadas de prevalência acometendo arcos, com 8 a $51 \%$ em região maxilar e $6 \%$ a $32 \%$ em região mandibular. As exostoses apresentam maior prevalência em pacientes do sexo masculino de etnia asiática, predominantemente chineses, seguidos de malasianos e indianos ${ }^{1-4}$.

Essas hiperplasias ósseas apresentam como características morfológicas a presença de osso cortical maduro e osso trabecular em regiões mais centrais da lesão. Em regiões mais periféricas, apresentam osso do tipo lamelar coberto pelo periósteo, normalmente com a presença de atividade osteoblástica reduzida, enquanto na região mais central essas hiperplasias caracterizam-se por trabéculas ósseas com anastomoses entre as quais existe uma pequena quantidade de medula óssea, sugerindo que a área central da exostose tem forte presença osteogênica ${ }^{5,6}$.

Possíveis achados em pacientes com a presença dessas protuberâncias possuem características multifatoriais, e assim, especula-se, por exemplo: predisposição genética, fatores parafuncionais mastigatórios, má oclusão, distúrbios da articulação temporomandibular, enxaqueca, aumento do consumo de peixes (ácidos graxos insaturados e vitamina) e consumo excessivo de cálcio e vitamina $D^{6,7}$.

Os tórus são alterações ósseas tipicamente assintomáticas exceto quando as lesões crescem para um tamanho que interfere com as atividades diárias, tais como mastigação ou fala. Essa patologia tende a crescer gradualmente ao longo da vida e não tem potencial para transformação maligna. Questões relacionadas aos portadores desta condição são 
apresentadas na dificuldade da pronuncia de alguns fonemas, disfagia, dor na mucosa bucal (principalmente relacionados a traumas locais), dificuldade na adaptação de próteses mandibulares, cálculos, osteíte, osteomielite ${ }^{1}$. Algumas lesões podem se assemelhar à esta condição, destacando-se como diagnóstico diferencial: fibroma ossificante, calcinose cutânea, osteoma e osteoma osteóide ${ }^{8-10}$.

Sua característica histopatológica é semelhante ao osso normal descrevendo-se osso cortical lamelar com a presença de canais de Havers, osteócitos normais e áreas dispersas de tecido conjuntivo. Estes achados constituem uma característica específica que permite aos patologistas diferenciar seu diagnóstico ${ }^{10}$. O objetivo deste relato de caso é expor uma condição extrema desta exostose mandibular, tendo como finalidade a melhora na qualidade de vida do paciente.

\section{CASO CLÍNICO}

O presente trabalho está de acordo com a declaração de Helsinque de 1975, revisada em 2000. O procedimento foi realizado em clínica privada, e o paciente autorizou a divulgação das imagens e do caso ao autor deste artigo por meio de termo de consentimento livre e esclarecido.

Este relato de caso foi conduzido de acordo com o guia para relatos de $\operatorname{casos}^{11}$ apresentando diagnóstico, procedimento terapêutico, acompanhamento e resultado obtido.

Paciente de 55 anos de idade, sexo masculino, melanoderma, sistemicamente hígido, compareceu à clínica privada, localizada na cidade do Rio de Janeiro (Rio de Janeiro, Brasil), com queixa principal de aumento de volume embaixo da língua. Durante a anamnese, não soube especificar o tempo de evolução, mas a acompanhante (irmã) informou que o mesmo se queixava desta região há pelo menos quatro anos, que o dificultava durante a mastigação de alguns alimentos, pois causava trauma no local. Neste momento, o paciente acrescentou a informação sobre a dificuldade na pronúncia de algumas palavras, sendo esta informação reforçada pela acompanhante.

Ao exame clínico intrabucal foi observado aumento de volume na região sublingual, bem delimitado, estendendo-se do elemento 42 ao 46 , ultrapassando a linha média, com coloração normal a mucosa e consistência firme, semelhante ao tecido ósseo, medindo aproximadamente $6 \mathrm{~cm}$ no seu maior diâmetro (Figura 1). Ao exame tomográfico foi observada imagem hiperdensa, de aspecto pedicular em relação ao corpo da mandíbula (Figura 2A e 2B), com maior altura de aproximadamente $1,5 \mathrm{~cm}$ no corte transaxial (Figura 3). Após a realização dos exames complementares foi agendado 0 procedimento operatório. Para tanto utilizou-se 15 mg de Dormonid (Roche ${ }^{\circledR}$, Rio de Janeiro, Brasil) para diminuição da ansiedade e sedação consciente, dois tubetes de anestésico local, Lidocaíca 2\% 1:100.000 de Adrenalina (DFL ${ }^{\circledR}$, Rio de Janeiro, Brasil). Após anestesia foi realizado descolamento mucoperiosteal do tecido que recobria a lesão com descolador do tipo Molt (Quinelato ${ }^{\circledR}$, Rio de Janeiro, Brasil), expondo-a por completo (Figura 4).

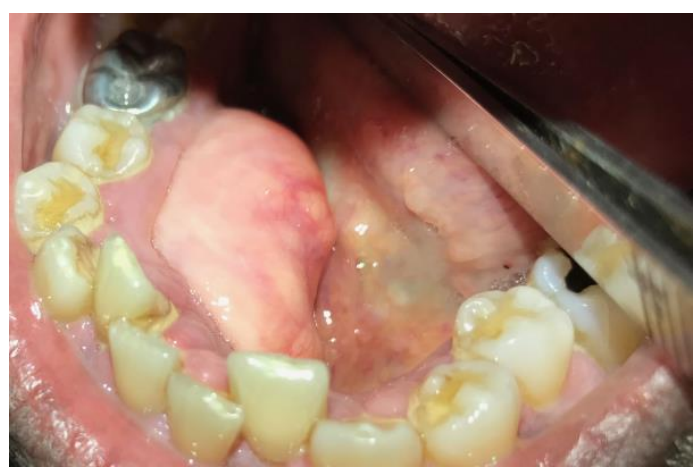

Figura 1: Aspecto clínico pré-operatório da exostose mandibular.

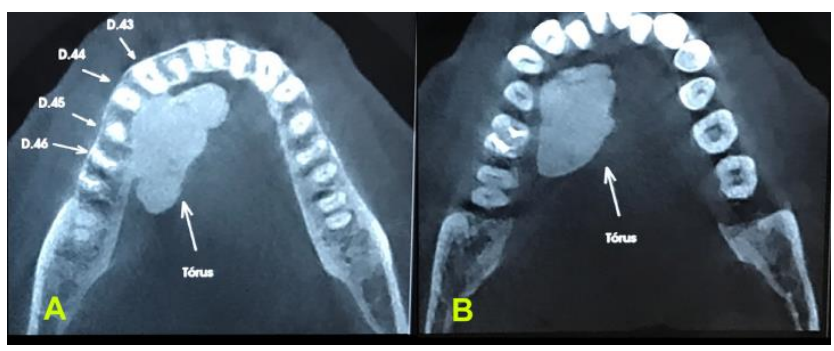

Figura 2: (A e B) Aspecto tomográfico da lesão no corte axial (seta)

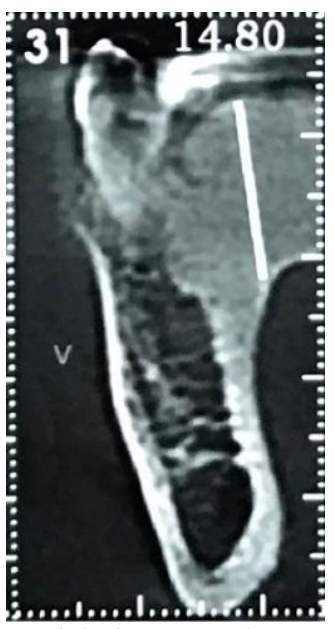

Figura 3: Corte transaxial, demostrando a região de maior altura da lesão, no corpo da mandíbula.

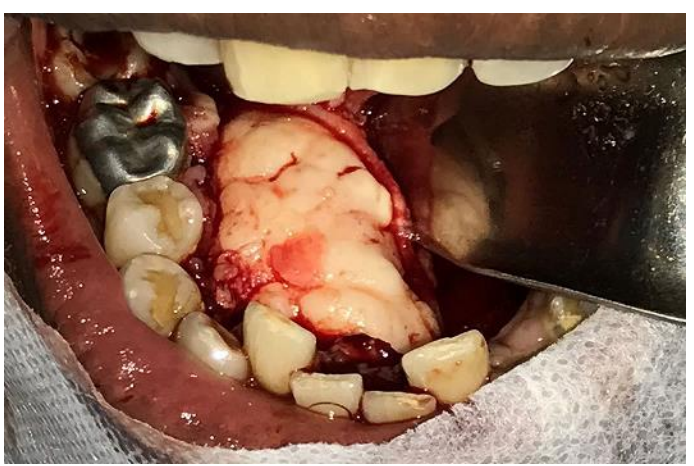

Figura 4: Imagem transoperatória da lesão, demostrando a grande massa óssea presente. 
Com isso, procedeu-se à remoção de fragmento para análise histopatológica e osteoplastia da lesão com uso de broca Zecrya de $28 \mathrm{~mm}$ (Wilcos do Brasil ${ }^{\circledR}$, Rio de Janeiro, Brasil). A síntese foi realizada com o fio 4-0 (0000). Para o pós-operatório foi prescrita medicação analgésica e antiinflamatória por três dias, Ibuprofeno $600 \mathrm{mg}$ cada seis horas (Eurofarma $^{\circledR}$, São Paulo, Brasil). O paciente foi orientado para alimentação macia pelo mesmo período e para auxiliar na higiene bucal foi prescrita clorexidina gel à $0,2 \%$ (Perioxidin gel $^{\circledR}$, Lacer, Brazil). A sutura foi removida após o sétimo dia; não foram observados sinais clínicos de infecção e o paciente, neste momento, não relatou dor.

Após este procedimento o laudo histopatológico confirmou a hipótese de exostose mandibular/ tórus mandibular.

$\mathrm{O}$ paciente seguiu em acompanhamento a cada quatro meses, pelo cirurgião assistente, até o final do primeiro ano (Figura 5), com orientações para retorno, caso haja um novo aumento do tecido ósseo na região.

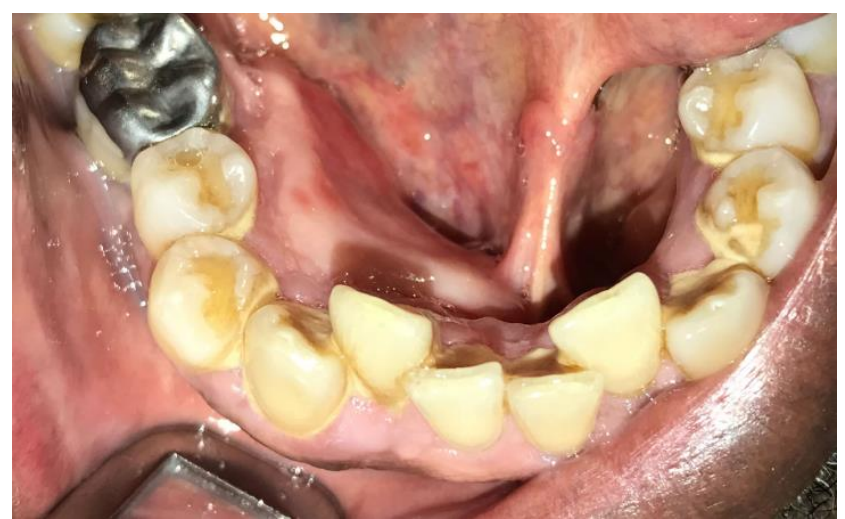

Figura 5: Imagem após a osteoplastia, com um ano de acompanhamento.

\section{DISCUSSÃO}

O importante deste caso é ressaltar a importância do diagnóstico diferencial de lesões ósseas extensas na região bucal e maxilofacial. No primeiro momento, devido ao caso apresentar-se unilateral, o que não é comum ${ }^{10}$. Isto, foi exposto, diante de outros cirurgiões, diferentes hipóteses diagnósticas, entre elas, o tórus mandibular e o osteoma. Este último, devido ao grande aumento na região, reforçado pelo tempo de evolução relatado pela a irmã do paciente.

A imagem tomográfica era compatível com ambas lesões (tórus e osteoma) ${ }^{10,12}$, o que poderia modificar a abordagem terapêutica, talvez levando a uma segunda intervenção cirúrgica para remoção completa do tumor.

$\mathrm{O}$ procedimento operatório visou uma melhora na qualidade de vida do paciente, diminuindo as queixas durante a alimentação e a dificuldade na pronuncia de alguns fonemas. E por apenas estes motivos, houve a intervenção cirúrgica, pois, na grande maioria dos casos, o acompanhamento clínico é a medida adotada. Desta forma, a principal indicação deste procedimento, não foi apenas o tamanho da lesão, mas principalmente estas questões funcionais, que corroboram com achados presentes na literatura ${ }^{1,9,10}$.

\section{CONCLUSÃO}

A osteoplastia realizada durante 0 procedimento operatório reduziu o tamanho do tórus mandibular, melhorando, desta forma, a qualidade de vida do paciente.

\section{REFERÊNCIAS}

1. Kumar Singh A, Sulugodu Ramachandra S, Arora S, Dicksit DD, Kalyan CG, Singh P. Prevalence of oral tori and exostosis in Malaysian population A cross-sectional study. J Oral Biol Craniofac Res. 2017;7(3):158-60.

2. Hiremath VK, Husein A, Mishra N. Prevalence of torus palatinus and torus mandibularis among Malay population. J Int Soc Prev Community Dent. 2011;1(2):60-4.

3. Sathya K, Kanneppady SK, Arishiya T. Prevalence and clinical characteristics of oral tori among outpatients in Northern Malaysia. J Oral Biol Craniofac Res. 2012;2(1):15-19.

4. Jainkittivong A, Apinhasmit W, Swasdison S. Prevalence and clinical characteristics of oral tori in 1,520 Chulalongkorn University Dental School patients. Surg Radiol Anat. 2007;29(2):125-31.

5. Kim YS. Pathogenetic growth potential in the central area of oral exostosis. Korean $\mathrm{J}$ Oral Maxillofac Pathol. 2013;37(5):201-10.

6. Morrison MD, Tamimi F. Oral tori are associated with local mechanical and systemic factors: A case-control study. J Oral. Maxillofac Surg. 2013;71(1):14-22.

7. García-García AS, Martínez-González JM, Gómez-Font R, Soto-Rivadeneira A, OviedoRoldán L. Current status of the torus palatinus and torus mandibularis. Med Oral Patol Oral Cir Bucal. 2010;15(2):e353-60.

8. Ladizinski B, Lee KC. A nodular protuberance on the hard palate. JAMA. 2014;311(15):1558-59.

9. Khan S, Shah SAH, Ali F, Rasheed D. Concurrence of torus palatinus, torus mandibularis and buccal exostosis. J Coll Physicians Surg Pak. 2016;26(11):111-13.

10.Kün-Darbois JD, Guillaume B, Chappard D. Asymmetric bone remodeling in mandibular and maxillary tori. Clin Oral Investig. 2017; 21(9):2781-88.

11.Riley DS, Barber MS, Kienle GS, Aronson JK, von Schoen-Angerer T, Tugwell $P$ et al. CARE guidelines for case reports: explanation and elaboration document. J Clin Epidemiol. 2017; 89:218-35. 
12.Kucukkurt S, Özle M, Baris E. Peripheral osteoma in an unusual location on the mandible. BMJ Case Rep. 2016; 2016. pii: bcr2016216554.

\section{CONFLITO DE INTERESSES}

Os autores declaram não haver conflitos de interesse.

AUTOR PARA CORRESPONDENCIA

Carlos Fernando de Almeida Barros Mourão moraocf@gmail.com

Submetido em 16/08/2018

Aceito em 04/10/2018 